\title{
Identification of some factors influencing soil transfer on shoes
}

\author{
Denis Werner ${ }^{1}$, Céline Burnier ${ }^{1}$, Yingchao $\mathrm{Yu}^{2}$, André R. Marolf ${ }^{1}$, Yuanfeng \\ Wang $^{2,3}$, Geneviève Massonnet ${ }^{1 *}$
}

${ }^{1}$ Ecole des sciences criminelles, University of Lausanne, Bâtiment Batochime, 1015 Lausanne-Dorigny, Switzerland

${ }^{2}$ Institute of Evidence Law and Forensic Science, China University of Political Science and Law, China

${ }^{3}$ Key Laboratory of Evidence Science, Ministry of Education, China

*Corresponding author: Genevieve.Massonnet@unil.ch

\begin{abstract}
In criminal activities, soil can be transferred from a crime scene to items linked with a perpetrator; for example, shoes, cars or tools. Several parameters will influence the quantity of soil transferred in a given scenario. The knowledge of the most influential factors can help the expert to assess the evidence using a logical approach at the activity level or to predict the amount of soil that can be expected in a given scenario. The influence of five chosen parameters, namely the shoe profile, shoe size, walker's weight, soil type and soil humidity were assessed using Design of Experiment (DOE) in order to understand their influence on soil quantity transferred on shoes.

The Faced Central Composite Design (FCCD) using a quadratic model was found to be highly significant, thus they could be adequately used to model and to interpret the amount of soil recovered from one shoe.

These designs demonstrate that the characteristics of the donor (soil type and soil humidity), as well as a combination of these two factors have a very significant impact on the soil transfer. The characteristics of the receptor (shoe profile, shoe size and walker's weight) also have an impact on the transfer but to a lesser extent.

Globally, this research provides valuable information for the forensic scientist both in investigative mode: evaluation of the soil quantity possibly transferred on shoes, and in the evaluative steps: is the quantity of soil found on the suspect shoes in accordance to the proposition/scenario given by the prosecution and the defence?
\end{abstract}

Keywords: Forensic geology; Soil forensic; Experimental design

\section{Highlights}

- Significant models were used to interpret the amount of soil recovered from shoes

- The factors linked to the donor soil had the most impact on the soil transfer

- A higher clay content influenced positively the quantity of soil collected

- The soil transfer increased with humidity to a maximum depending on soil types

- Other shoe sole properties seemed to have a more important role than the profile 


\section{Introduction}

Transfer parameters are very important in a forensic context, in either an investigative or evaluative approach, to assess the evidential value of microtraces at the activity level. Over the years, several studies have been carried out for materials such as textile fibres [1-7], paints [8, 9], glass [10-14] or glitter particles [15, 16]. However, there has been a lack of this type of research for soils, although, the last few years, increasing interest in the forensic analysis of soil was revealed as it has sometimes been the only available evidence in some cases [17-21]. The forensic soil expert would generally either provide investigative leads - for example by inferring soil origins - or carry comparative analysis between a trace (e.g. found on a textile or on shoes from a suspect) and a reference (e.g. an area where a body was buried).

In a literature review based on real caseworks, Von Däniken [22] found that amongst the items belonging to suspects, shoes are the most common support for soil traces $(40 \%)$, followed by clothing $(24 \%)$ and the external surfaces of vehicles $(17 \%)$. These data are supported by Pye [23] who stated that in soil cases "probably the most frequently encountered are items of footwear and clothing".

The transfer of soil to shoes or other supports is affected by weather conditions such as rainfall, temperature or humidity [23]. It is therefore necessary for the expert to have more knowledge about meteorological data to assess the probability that soil would be transferred to shoes or other supports. However, very few studies have focused on the soil transfer to shoes, and more specifically on the different parameters influencing the quantity of soil transferred. This quantity is an important parameter both for investigative and evaluative purposes, and it will also influence the selection of the analytical sequence. Most sequences request a soil quantity of approximately $1 \mathrm{~g}$ [24] cited Ruffel et al. [21]. Smaller sample size might require a specific and different comparison approaches.

References concerning soil transfer focus mainly on the assessment of the variability between a trace and a given source. Dudley and Smalldon [25] simulated soil transfer on shoe soles. Soils were watered to maximise the transfer and the quantity of soil was estimated to be approximately $10 \mathrm{~g}$ per shoe. Colour (dry and ashes), $\mathrm{pH}$, saccharide level and particle size distribution were compared: all the data obtained from the trace, except the saccharide content, were undifferentiated from their source. Croft and Pye [26] walked on four types of soil with five different types of shoes. The amount of transferred soil was not reported, but it was found out that the trace material could be linked to a soil source even though selective transfer would happen. Chazottes et al. [27] simulated crime scenes on two different locations with watered soil to compare the particle size distributions between suspect and control soil samples using a sieving procedure. Coarse fractions were lost in most of the suspect samples and differences to the control soil were based on extreme size classes' differences (coarse and very small grains). Thus, significant differences within medium size classes of particles (1 - 0.063 $\mathrm{mm}$ ) should be considered as a sign of dissimilarity between the samples. Unfortunately, the quantity of soil was not reported in this article. Morgan et al. [28] studied the sequential transfer of soil on footwear and its persistence with flatsoled training shoes. Transfer was tested using plasticine and persistence was assessed according to the activity (walking/running) of the wearer of the shoes. They noticed that walking did not disturb the sequential chronology of the layers, but running caused the different layers to become mixed together. It was shown that the preservation of soil layers varied depending on the area of the sole. The amount of transferred soil was not reported, but a rapid loss of material was observed after $100 \mathrm{~m}$, with some particles still adhering the sole after $450 \mathrm{~m}$. Stoney et al. [29] investigated the effects of walking sequentially at three different sites with two different types of shoes. Soil samples were collected by walking on paper for weakly adhering particles, with an electrostatic lifter for the moderately adhering particles and through moist swabbing for the strongly adhering particles. Microscopic analysis showed that soil from the last site visited was always the most present on the sole, and that the final exposure had removed the particles transferred through the previous exposures. Particles on the surface of the footwear were easily lost and replaced but no indication of the amount of soil 
present was mentioned. Woods et al. [30] proposed a protocol to analyse residues collected from shoes and shovels and to determine whether a match could be found between the analytical results from the traces and from defined scenes. The quantity of soil collected at different locations was reported to vary between $4.8-35.0 \mathrm{~g}$ on shoes. This study demonstrates that comparative soil analysis can correctly exclude or show association between a trace and a source with a high level of discrimination between different sources. In summary, these different studies showed that soil traces could be linked to their source using a common and recommended analytical procedure.

The study of Murray et al. [19] is, to our knowledge, the only reported investigation into understanding soil transfer onto textile items (e.g. a bra) when a body is dragged on the ground. Their research was based on an Australian homicide case where soil was found on a victim's clothing, suggesting that she was attacked in her garden and not at the place where the body was found. Transfer patterns were observed and were found to be specific to a given source of soil. The quantity of soil transferred to textiles was measured by image processing analysis. Their results show that soil type and moisture were the most influential factors on the quantity of soil transferred. They highlighted that quantity/repartition of soil transferred was more important when the question was " [...] not about the complexities of the soil science, but the much more fundamental question of how the soil was deposited on the clothing" [19].

The expert may be asked to evaluate his/her findings with respect to particular competing alleged activities set by the specific case circumstances [31]. As an illustration, imagine a case where a victim is deposited in the forest in a rainy April day. The alternative hypothesis put forward by the suspect is that he walked at the same location on a dry summer day. The amount/repartition of soil on his shoes is expected to be different due to the weather changes in these both situations, but the soil itself is expected to be not differentiated. In investigative mode, the question would be: do we need to search for soil traces? Given the weather conditions and the soil type, which quantity soil do we expect under the suspect's shoes? The quantity of soil transferred could be used to allow a proper evaluation of the evidence, as it can be a help to predict the expected amount of soil transferred in a given scenario. In an evaluative approach, it can provide information to answer the following question: does the quantity of soil found on the suspect's shoes corroborate the proposal given by the prosecution and/or the defence?

The present paper aims to study the transfer of soil on shoes to provide helpful information for forensic scientists to allow investigation and interpretative evaluation. The main purpose was to determine which factors most significantly affect the transfer of soil on shoes, in order to obtain a more comprehensive overview of the transfer process. In this regard, five factors were selected based on the literature: shoe profile, shoe size and the weight of the walker were chosen as receptor parameters, and the type of soil and the humidity as donor parameters. As five factors were considered in this study, a multivariate statistical approach is recommended to study the effect of all the parameters with minimal experiments [32]. Experiments were carried out using design of experiments (DOE) as this enables the exploration of all possible combinations of parameters variations within the experimental ranges [33]. The advantage of DOE compared to an univariate approach is the possibility to collect data and analyse them with proper statistics to obtain maximal information, such as important factors affecting the targeted response (here, the amount of soil transferred). Additionally, DOE allows the consideration of interactions between the different factors, resulting in the construction of a response surface plot, which helps to understand how soil transfer happens and how it is affected by the different factors.

\section{Material and Methods}

Based on previous researches [22, 23, 26, 34], five target parameters known to be interesting for transfer study were selected, two of them linked to the receptor or support (i.e. the shoes), two linked to the donor (i.e. the soil and the humidity) and one linked to the person. Additionally, gait and variation due to the person itself were not studied. 


\subsection{Shoe profile}

The shoe profile describes the depth of the shoe print, which is in direct contact with the soil surface while walking. The volume and pattern of the shoe profile influence its ability to retain soil traces. As the study was conducted in Switzerland, the choice of the shoes for the experiments was based on Swiss police databases [34] as Croft and Pye [23] based their choice on most common types of footwear encountered in routine laboratory examinations. Three main types of shoes were reported: low profile shoes with soft elasticity sole, such as Adidas ${ }^{\circledR}$ Superstar or Converse ${ }^{\circledR}$ All Star training shoes, medium profile shoes with soft elasticity sole, such as Nike ${ }^{\circledR}$ Air training shoes and high profile shoes with hard elasticity sole, such as Caterpillar ${ }^{\circledR}$ or Swiss military shoes. The selected shoes, Converse ${ }^{\circledR}$ All Star, Nike $®$ Air and Swiss Military shoes are illustrated in Figure 1. All shoes were brand new. No attempt was made to objectively quantify the sole profile, but they were used as continuous factors in the DOE, as they illustrate generically low, medium and high profiles, which corresponding respectively to the following levels: -1 for low profile, 0 or central point for medium profile and +1 for high profile.

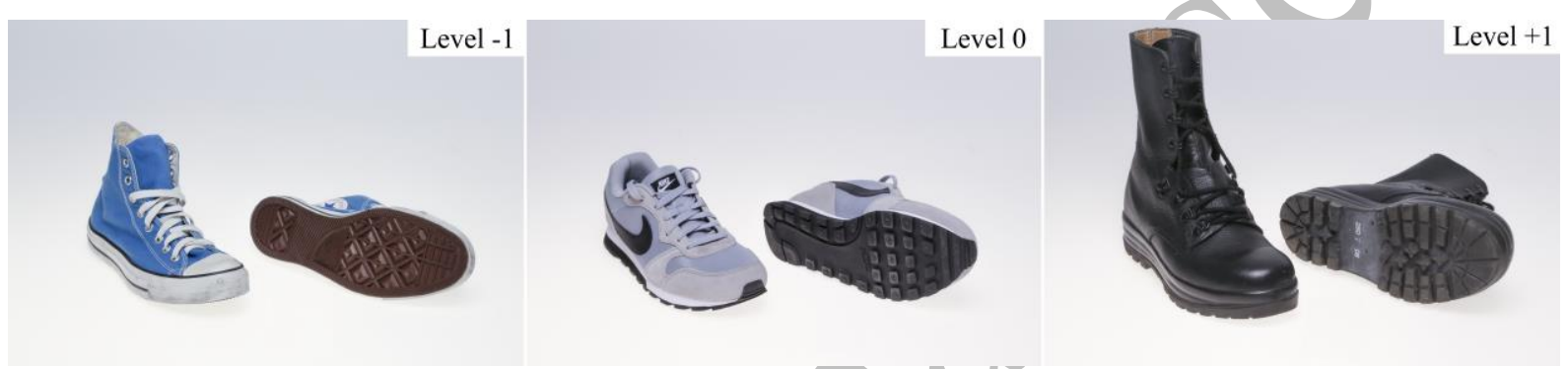

Figure 1. Photography of three types of shoes chosen: low profile (level -1), Converse® All Star; medium profile (level $0)$, Nike ${ }^{\circledR}$ Air training; high profile (level +1$)$, Swiss Military shoes.

\subsection{Shoe size}

As intervariability linked to specific individual characteristics (e.g. gait) was not studied here, the lower level (level -1) was set as the usual experimenter shoe size (i.e. EUR 38). Level 0 was set at EUR 40 and level +1 at EUR 42 . All the different profiles were used in the three sizes for the experiments. In comparison, the distribution of shoes seized by Swiss police range from 36 to 46 Euro sizes for men $(\mathrm{N}=1736)$ and from 33 to 43 Euro sizes for women $(\mathrm{N}=116)$ [34]. The most common size for men is $42(27.6 \%)$ and 38 for women $(48.4 \%)$.

\subsection{Weight of the person wearing the shoes}

With respect to walker's weight, the following weights were chosen: $52 \mathrm{~kg}$ was set as -1 low level, $72 \mathrm{~kg}$ as +1 high level and $62 \mathrm{~kg}$ as the 0 centre sample. As stated previously, in order to reduce the influence of the wearer of the shoes, a single volunteer weighting $52 \mathrm{~kg}$ was chosen to conduct the whole experiment. A loaded backpack of $10 \mathrm{~kg}$ or $20 \mathrm{~kg}$ was used to reach the centre and the high level. According to Swiss medical references [35, 36], the average body weight for women is around $60 \mathrm{~kg}$ and $75 \mathrm{~kg}$ for men.

\subsection{Soil type}

Two soils were chosen according to their expected differences in total organic carbon (TOC). High organic soil (level +1$)$ was sourced from a forest, where the upper layer, made of organic debris and leaf litter, was first removed before soil 
collection. Low organic soil (level -1) was sourced from a freshly ploughed field. Both sample sites were located $300 \mathrm{~m}$ apart. A 50:50 (\% w/w) mixture of these two soils represented the 0 value or centre point of the DOE. Large amounts of soils (about $10 \mathrm{~kg}$ ) were collected and kept in shallow containers as proposed by Croft and Pye [26]. Both soils exhibited a silty loam texture.

The composition and physical characteristics of the soils are measured on the $<200 \square \mathrm{m}$ fraction and described in Table 1. The $\mathrm{pH}\left(\mathrm{H}_{2} \mathrm{O}\right)$ was measured according to [37, 38] using a Mettler Toledo SevenGo2 pH-meter. The colour of the soils was determined under a standardised daylight source (Macbeth Judge II) using the Munsell Soil Color Charts (2009 Revised Edition) [39]. TOC [\%] was measured by weighing before and after 2 hours dry combustion at $450{ }^{\circ} \mathrm{C}$ in a tube furnace (Carbolite, MTF 10/15/130) for $100 \mathrm{mg}$ of dry soil. Particle size distribution was measured by LD-PSD (LA-960 Partica, Horiba Scientific) and soil texture was then calculated by clay, silt and sand composition, following the United States Department of Agriculture textural classification triangle [40].

\begin{tabular}{|c|c|c|c|c|c|c|}
\hline Type of soil & ID & $\begin{array}{l}\text { PH Value } \\
\left(\mathrm{H}_{2} \mathrm{O}\right)\end{array}$ & Dry Colour & TOC [\%] & $\begin{array}{l}\text { Particle Size } \\
\text { Distribution }\end{array}$ & Soil Texture \\
\hline $\begin{array}{l}\text { Soil sample } 1 \\
\quad \text { (Soil 1) }\end{array}$ & $\begin{array}{l}\text { LS_Field } \\
2016\end{array}$ & $6.7 \pm 0.1$ & $\begin{array}{l}\text { Light brownish grey } \\
2.5 \mathrm{Y} / 6 / 3\end{array}$ & & $\begin{array}{l}\text { Clay }(5.7 \%) \\
\text { Silt }(61.5 \%) \\
\text { Sand }(32.8 \%)\end{array}$ & Silty loam \\
\hline $\begin{array}{l}\text { Soil sample } 2 \\
\quad \text { (Soil 2) }\end{array}$ & $\begin{array}{l}\text { LS_Wood } \\
2016\end{array}$ & $6.9 \pm 0.3$ & Grey 10YR/ & $15.6 \pm 4.2$ & $\begin{array}{c}\text { Clay }(0.3 \%) \\
\text { Silt }(53.2 \%) \\
\text { Sand }(46.5 \%)\end{array}$ & Silty loam \\
\hline $\begin{array}{c}\text { Mixed sample Soil } 1 / \text { Soil } 2 \\
\text { (Mix 50/50) }\end{array}$ & $\begin{array}{l}\text { LS_Mix } \\
2016\end{array}$ & $6.9 \pm 0.2$ & $\begin{array}{c}\text { Greyish brown } \\
2.5 \mathrm{Y} / 5 / 2\end{array}$ & $6.7 \pm 0.8$ & $\begin{array}{c}\text { Clay }(0.5 \%) \\
\text { Silt }(60.4 \%) \\
\text { Sand }(39.1 \%)\end{array}$ & Silty loam \\
\hline
\end{tabular}

Table 1. Soil samples characteristics.

\subsection{Soil humidity}

Soil humidity (also called soil moisture content or soil water content) is the quantity of water contained in soil. In this study, $25 \%$ (w/w) soil humidity was chosen as -1 low level, $55 \%$ (w/w) as +1 high level and $40 \%$ (w/w) as 0 centre sample. The low level was chosen to allow enough transfer to get over $0.5 \mathrm{~g}$ of soils.

\subsection{Methodology}

The following methodology was used for the data generation and traces collection (Figure 2). Soils were prepared before the experiment, water was added in a controlled way in order to get proper humidity content. One single experimenter walked for 50 steps in the soil containers with each different shoe type and shoe size. Weight variation was generated using a loaded backpack worn by the walker. The shoes were collected, weighed and dried at $50^{\circ} \mathrm{C}$ for $30 \mathrm{~min}$. The soles were then scraped, and the collected soil was dried further in the oven. Finally, the collected amount of soil was weighed and considered to be representative of the soil available on the shoe during the transfer. 


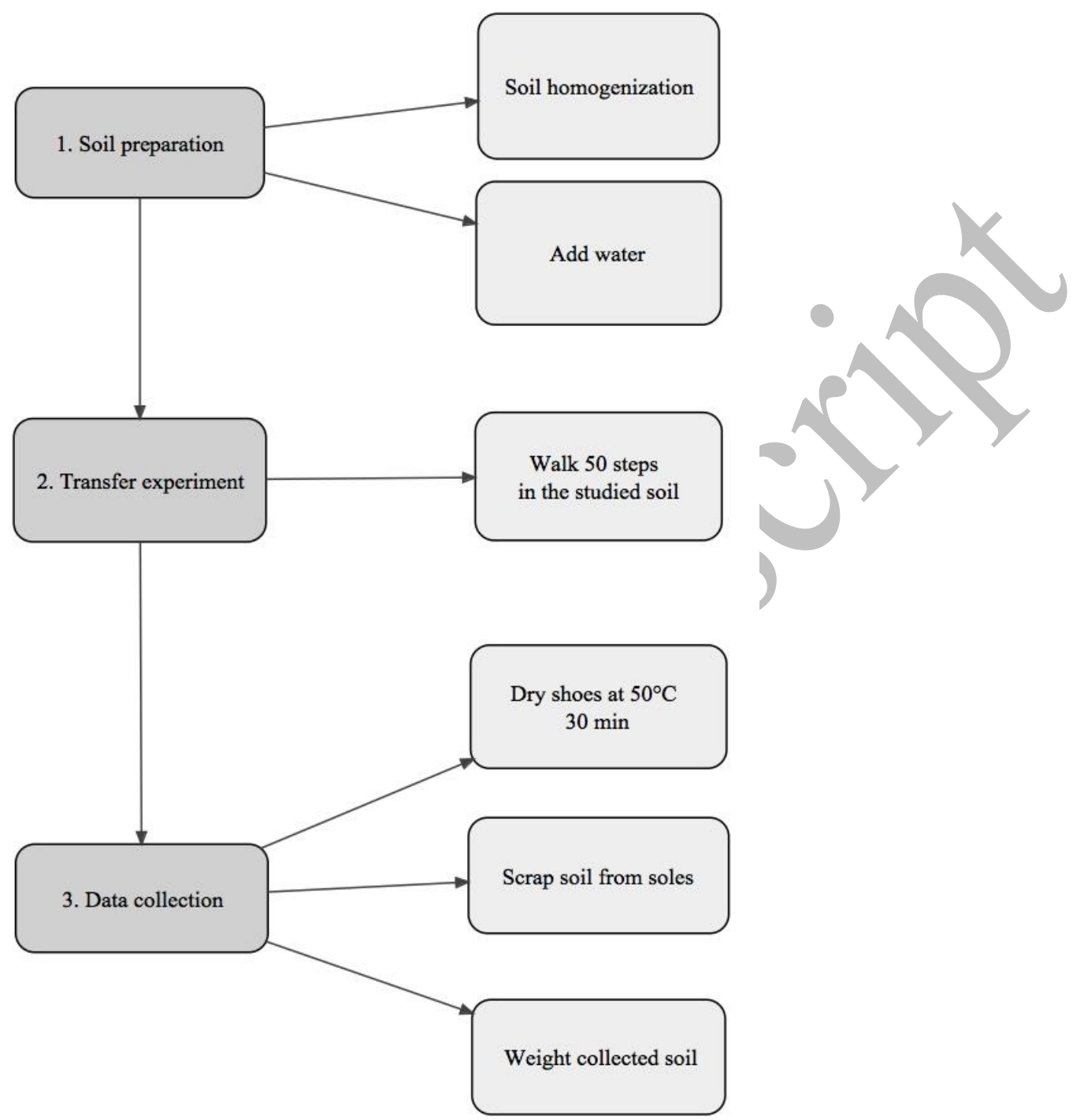

Figure 2. Data generation and collection process.

\subsection{Experimental designs}

Unscrambler® X 10.1 software (CAMO Software AS., Oslo, Norway, 2009) was used to create and to analyse the experimental designs. The selected response was the amount of soil recovered from one shoe (left or right) by scrapping. In factorial screening experiments, the significance of each factor was assessed. The factors of the model were examined by analysis of variance (ANOVA) and Snedecor's F-test [41] and the curvature of the model was checked by Student's t-test [33, 41, 42]. In the experimental optimisation, a mathematical model for each response surfaces could be built for the response fitting a second order polynomial function by the least square methodology [41, 43]. Models were validated by evaluating lack-of-fit and regression significance by ANOVA and Snedecor's F-test. A significance level at $95 \%$ confidence level was considered, so the significance or the risk level $(\alpha)$ was equal to 0.05 .

\subsubsection{Selection of the factors and their levels}

Factors selected for this study as described under 2.1 to 2.5 are shoe profile, size, walker weight, soil type and humidity. Temperature was not considered as a parameter in this study which was conducted at the ambient temperature of the 
laboratory (approximately $20^{\circ} \mathrm{C}$ ). The experimenter was always the same person, so interpersonal factors, like gait, were not considered, although it could influence the soil transfer. These factors are summarised in Table 2.

\begin{tabular}{|c|c|c|c|}
\hline Factor & Level -1 & Level 0 & Level +1 \\
\hline A - Profile [-] & Low (Converse ${ }^{\circledR}$ All Star) & Medium (Nike $®$ Air) & High (Swiss Military) \\
\hline B - Weight [kg] & 52 & 62 & 72 \\
\hline C - Size [EUR] & 38 & 40 & 42 \\
\hline D - Type of soil & Soil 1 & Mix $50 / 50[\% \mathrm{w} / \mathrm{w}]$ & Soil 2 \\
\hline E - Humidity [\% w/w] & 25 & 40 & 55 \\
\hline
\end{tabular}

Table 2. Factors and level values used in the experimental design. In this table, profile was considered as continuous factors although they are not quantified.

\subsubsection{Full Factorial Design}

A Full Factorial Design (FFD) was used to allow the screening of factors and to determine the interactions between factors and their importance $[33,44]$. Five factors were studied, leading then to $2^{5}=32$ experiments. In order to be able to measure the experimental error, the amount of soil recovered from one shoe is considered as one experiment, so each experiment was replicated twice (i.e. one for each shoe, left and right). Five centre samples (also called centre points) were added to estimate the curvature in the effect and the error variance. Therefore, 69 experiments were done for the FFD.

\subsubsection{Faced Central Composite Design}

Given the results of screening the factors with FFD, a Faced Central Composite Design (FCCD) - a response surface design - was selected to analyse the five factors and describe response variations in experimental domain as precisely as possible $[33,44]$. This design is an extension of FFD that can be fitted to a quadratic model. Each experiment was performed only once, but one FCCD was performed for each shoe - left and right. Four centre samples were provided for each DOE (see Section 3.2). For this design 14 more experiments were added to the one done in the FFD (32) for a total of 46 points of each shoe. The best significant model for response surfaces of each DOE was validated and chosen by minimising the $\mathrm{p}$-values of the regression significance F-tests and in the same time by maximising the p-value of the lackof-fit F-tests [42].

\subsection{Extended study of the interaction between soil type and humidity}

As the results of DOE indicated that the combination of soil types and humidity was one of the most influential factors, further transfer studies were carried out varying only these two parameters. The shoe profile chosen was the central point (Nike® Air), size 38 with a walker weight of $52 \mathrm{~kg}$. The amount of soil was calculated on one shoe. The two selected soils were investigated by varying their humidity content from $10 \%$ to $80 \%$ in $5 \%$ increments. Triplicate experiments $(n=3)$ were conducted and one person walked 50 steps in the soil containers. The amount of soil transferred on a single shoe was only considered if it was higher than $0.5 \mathrm{~g}$. 


\section{Results}

\subsection{Full Factorial Design (FFD)}

The first part of this research consisted in studying the significance of the five factors, their interactions and their effects with a screening design - the FFD. For all experiments for the FFD, the global amount of soil transferred to one shoe ranged from $0.04-60.44 \mathrm{~g}$. The raw data associated with the FFD experiments and the results are available respectively in Table S1 and Table S2 in Appendix.

These results showed that all factors impacted the amount of soil recovered from one shoe, except for the walker weight (factor B). The latest was the only factor that is never significant, even when coupled to other significant factors. Curvature was studied and was shown to be highly significant (p-value < 0.0001). Application of the FFD created model was not possible as its $p$-value was extremely significant ( $p$-value $<0.0001$ ). The non-significance of lack-of-fit ( $p$-value $=$ 0.26539) allowed to assume that all main effects are linear in this model. In our case, the curvature indicated that the data were following a quadratic model. Therefore, an extension of FFD to FCCD was considered as necessary after curvature analysis. It was decided not to take off any factors for the FCCD design as the FFD model was not found to be adequate. Additionally, it was quite surprising that weight (factor B) was not significant, as it could be expected that the higher the weight, the more the transfer. Data analysis showed differences between the collected amount of soil on the left and right shoes, thus indicating influence from gait. These considerations will be taken into account for the FCCD.

\subsection{Faced Central Composite Design (FCCD)}

A FCCD was performed based on the results of the FFD. All raw data associated with the FCCD experiments are available in Table S3 in Appendix. Each experiment was performed only once, with one FCCD for each shoe - left and right. Four centre samples were used for the design of the left shoe and three for the right shoe. In this last DOE, the analysis of residuals allowed the identification of the presence of an outlier in the central samples. This outlier had a larger residual than the others. Thereby, it was decided to exclude it and to use only three centre points for the DOE of the right shoe. For all experiments for the FCCD, the total amount of soil transferred to the left and right shoes ranged respectively from $0.04-43.96 \mathrm{~g}$ and $0.04-49,33 \mathrm{~g}$. Medians of the quantity recovered on both feet were closed (around $35 \mathrm{~g}$ of soil), but a higher variability was observed on the right shoes, thus confirming the influence of the gait on the transfer.

The best significant model for response surfaces of each DOE was validated and chosen by minimising the p-values of the regression significance F-tests and in the same time by maximising the p-value of the lack-of-fit F-tests [42]. The pvalue of regression significance for each DOE of left and right shoes was highly significant ( $\mathrm{p}$-value $<0.001$ ). Therefore, as these two models were highly significant, thus they could be adequately used to model and to interpret the amount of soil recovered from one shoe. The quadratic part of each model was also highly significant (p-value $<0.001$ ), which showed that they were useful for the conception of models. On the contrary, the linear parts were non-significant for both DOE (p-value $=0.0725$ and 0.6281), which followed the results of FFD. The lack-of-fit was also non-significant for these two DOE for left and right shoe ( $\mathrm{p}$-value $=0.0514$ and 0.9882 ), so they were trusted to describe the response surfaces adequately.

Statistical analysis of the FCCD revealed a significant quadratic effect of all the factors, as shown in Table 3, except for the factor B that is non-significant for the right shoe. On the contrary, the linear parts were non-significant for both DOE, which followed the results of FFD. The interaction between soil type and humidity (DE) kept being significant and had a positive effect on the quantity of soil transferred for both models. The lack-of-fit was also non-significant for these two 
DOE, so these models were trusted to describe the response surfaces adequately, using all the factors. The p-value of regression significance for each DOE of left and right shoes was highly significant ( $\mathrm{p}$-value $<0.001)$. Therefore, our model can be trusted as representative of the soil transfer important and used to interpret the amount of soil recovered from one shoe.

\begin{tabular}{|c|c|c|c|c|}
\hline \multirow{2}{*}{ Effects } & \multicolumn{2}{|c|}{ Left shoe } & \multicolumn{2}{|c|}{ Right shoe } \\
\hline & Significance & Effect value & Significance & Effect value \\
\hline Profile (A) & $N S$ & N/A & $N S$ & $N / A$ \\
\hline Weight (B) & $N S$ & $N / A$ & $N S$ & $N / A$ \\
\hline Size $(C)$ & $N S$ & N/A & $N S$ & $N / A$ \\
\hline Type of soil (D) & -- & -3.8688 & $N S$ & N/A \\
\hline Humidity (E) & $N S$ & N/A & $N S$ & $N / A$ \\
\hline Profile * Weight $(\mathrm{AB})$ & $N S$ & N/A & $N S$ & $N / A$ \\
\hline Profile * Size (AC) & $N S$ & N/A & $N S$ & $N / A$ \\
\hline Profile * Type of soil (AD) & $N S$ & N/A & $N S$ & N/A \\
\hline Profile $*$ Humidity $(\mathrm{AE})$ & $N S$ & $N / A$ & $N S$ & N/A \\
\hline Weight $*$ Size $(B C)$ & $N S$ & $N / A$ & $N S$ & $N / A$ \\
\hline Weight $*$ Type of soil (BD) & $N S$ & $N / A$ & $N S$ & $N / A$ \\
\hline Weight $*$ Humidity $(\mathrm{BE})$ & $N S$ & $N / A$ & $N S$ & $N / A$ \\
\hline Size * Type of soil (CD) & $N S$ & $N / A$ & $N S$ & $N / A$ \\
\hline Size $*$ Humidity $(\mathrm{CE})$ & $N S$ & $N / A$ & $N S$ & $N / A$ \\
\hline Type of soil * Humidity (DE) & + & 2.9325 & +++ & 4.7913 \\
\hline Profile $*$ Weight $*$ Size $(\mathrm{ABC})$ & NS & $N / A$ & $N S$ & $N / A$ \\
\hline Profile $*$ Weight $*$ Type of soil (ABD) & $N S$ & $N / A$ & $N S$ & $N / A$ \\
\hline Profile $*$ Weight $*$ Humidity $(\mathrm{ABE})$ & $N S$ & $N / A$ & $N S$ & $N / A$ \\
\hline Profile $*$ Size $*$ Type of soil (ACD) & $N S$ & $N / A$ & $N S$ & $N / A$ \\
\hline Profile $*$ Size $*$ Humidity $($ ACE $)$ & $N S$ & $N / A$ & $N S$ & $N / A$ \\
\hline Profile * Type of soil * Humidity (ADE) & $N S$ & N/A & $N S$ & $N / A$ \\
\hline Weight $*$ Size $*$ Type of soil $(B C D)$ & $N S$ & N/A & $N S$ & $N / A$ \\
\hline Weight $*$ Size $*$ Humidity $(B C E)$ & $N S$ & N/A & $N S$ & $N / A$ \\
\hline Weight $*$ Type of soil $*$ Humidity (BDE) & $N S$ & N/A & $N S$ & N/A \\
\hline Size * Type of soil $*$ Humidity (CDE) & $N S$ & $N / A$ & $N S$ & $N / A$ \\
\hline Profile * Profile $(\mathrm{AA})$ & +++ & 15.2657 & +++ & 19.8946 \\
\hline Weight $*$ Weight $(\mathrm{BB})$ & +++ & 16.7757 & $N S$ & N/A \\
\hline Size * Size $(C C)$ & +++ & 16.6257 & +++ & 24.3746 \\
\hline Type of soil $*$ Type of soil (DD) & --- & -49.6443 & --- & -44.0954 \\
\hline Humidity $*$ Humidity $(\mathrm{EE})$ & -- & -55.9143 & -- & -61.1754 \\
\hline
\end{tabular}

Table 3. Analysis of significance of the effects on the amount of soil after applying FCCD. " $N S$ ": Non-significant (p-value $\geq 0.05$ ), “-”: weakly negative effect (p-value = [0.01:0.05]), “--”: moderately negative effect (p-value = [0.005:0.01[), “---”: highly negative effect (p-value < 0.005), “+”: weakly positive effect (p-value = [0.01:0.05]), “++”: moderately positive effect (p-value = [0.005:0.01[), “+++": highly positive effect (p-value < 0.005). "N/A": Not applicable.

The two FCCD models allowed surface response plots to be constructed. Only the left shoe surface response plots were illustrated in Figure 3, as significant differences were not presented between both shoes. It was chosen to illustrate only three of them as they were the most relevant. 
Surface responses indicated that more soil was collected on the low (Converse ${ }^{\circledR}$ ) and high (Military) shoe profiles rather than on the medium shoe profile (Nike $\circledR$ ) and at the central points for the mix soil (Figure 3a) and humidity $40 \%$ (Figure $3 b)$. Figure $3 \mathrm{c}$ indicated that the highest amount of soil would be transferred to the chosen central point: mixed soil and $40 \%$ humidity.

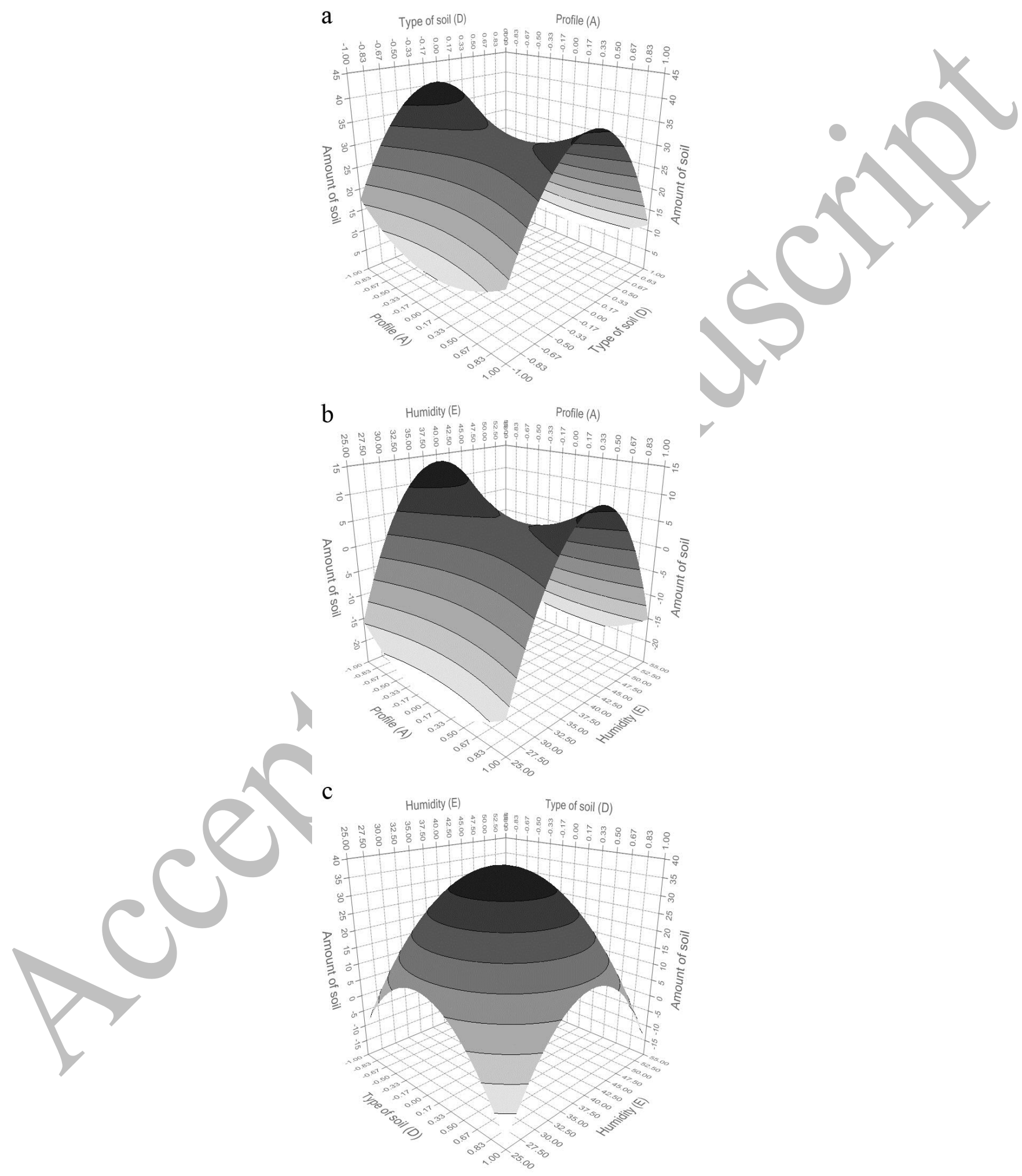

Figure 3. Surface response plots for the left shoe. a) Models the relation between the profile and the type of soil. b) Models the relation between the profile and the humidity. c) Models the relation between the type of soil and the humidity. The darker the surface, the higher the response. 


\subsection{Extended study of the interaction between soil type and humidity}

A total of 60 transfer experiments were carried out to better understand the transfer process. Figure 4 illustrates the quantity of soil transferred on one shoe as a function of humidity for both soils.

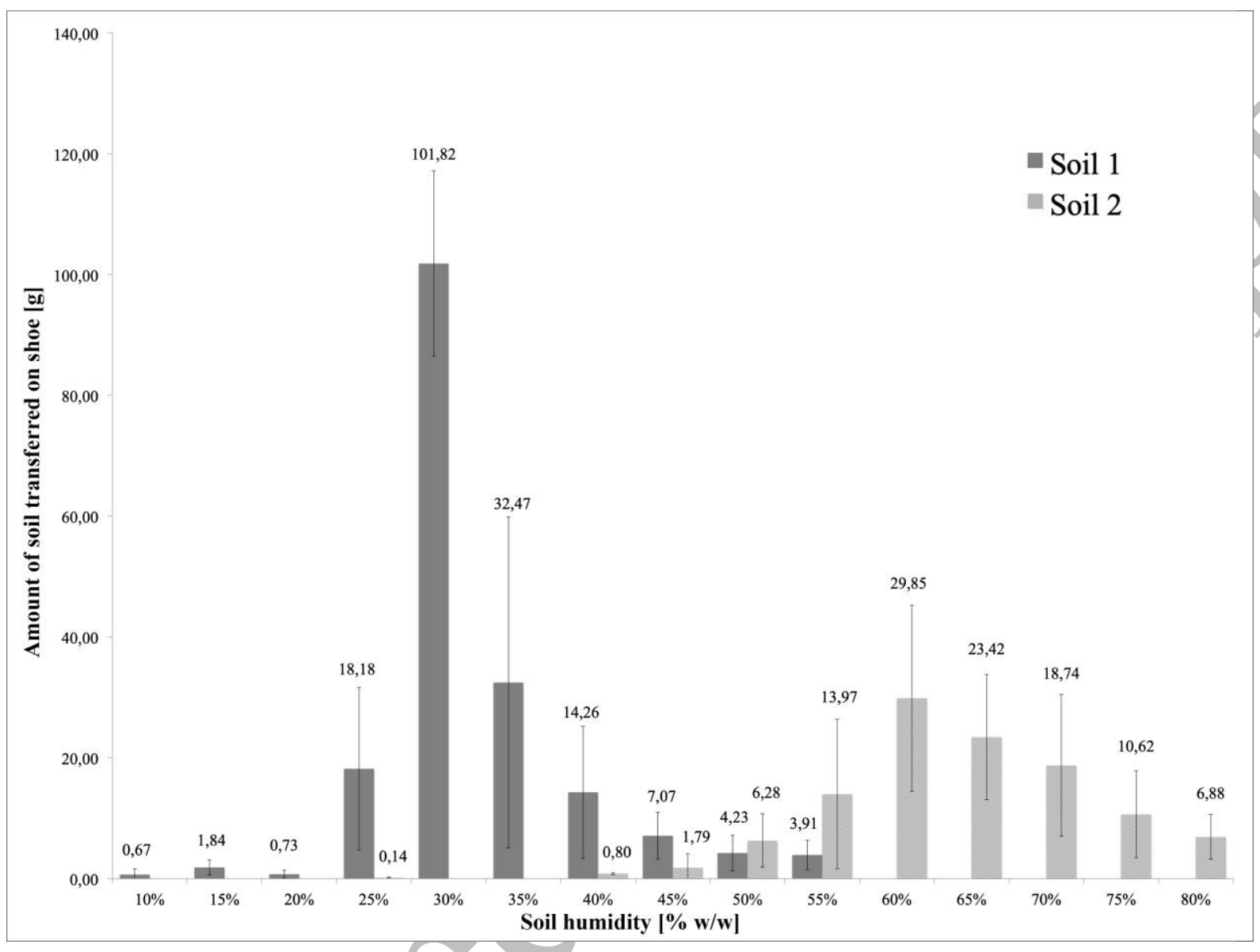

Figure 4. Quantity of soil transferred on Nike Air shoes (size Euro 38) for soil 1 and 2, standard deviations of the 3 experiments are indicated as error bars.

As shown in Figure 4, the humidity levels necessary to set a transfer was clearly depending on the soil type. The amount of soil transferred increased with percentage humidity until a maximum, which was different for both soil types, following their organic content: soil 2 needed over $60 \%$ to reach the maximum, whereas soil 1 only needed $30 \%$.

For all scenarios, the total amount of soil transferred to one shoe ranged from $0.09 \mathrm{~g}$ to $115.28 \mathrm{~g}$. The maximum quantity of soil transferred was around three times higher for soil 1 (101.82 g) than for soil 2 (29.85 g). The results showed that the humidity ranges allowing a transfer to shoes of more than $0.5 \mathrm{~g}$ of soil was clearly different for soil $1(10 \%-55 \%)$ and soil sample $2(40 \%-80 \%)$. Once the maximum of humidity was reached, a decrease in the transferred quantity was observed as the humidity level kept increasing. Indeed, saturation of the surface was obvious as a thin layer of water covered the soil. The amount of soil deposited on shoe soles as a function of humidity and soil type is illustrated in Figure 5a, for soil 1. At $30 \%$ humidity, the highest quantity of soil was transferred; the soil became then very liquid as illustrated for $40 \%$ and $50 \%$ humidity. These observations are similar for soil 2 (Figure 5b), but less visible as the quantity of soil transferred is less variable. As illustrated, the global amount of soil transferred is notably higher for soil 1 than for soil 2. 


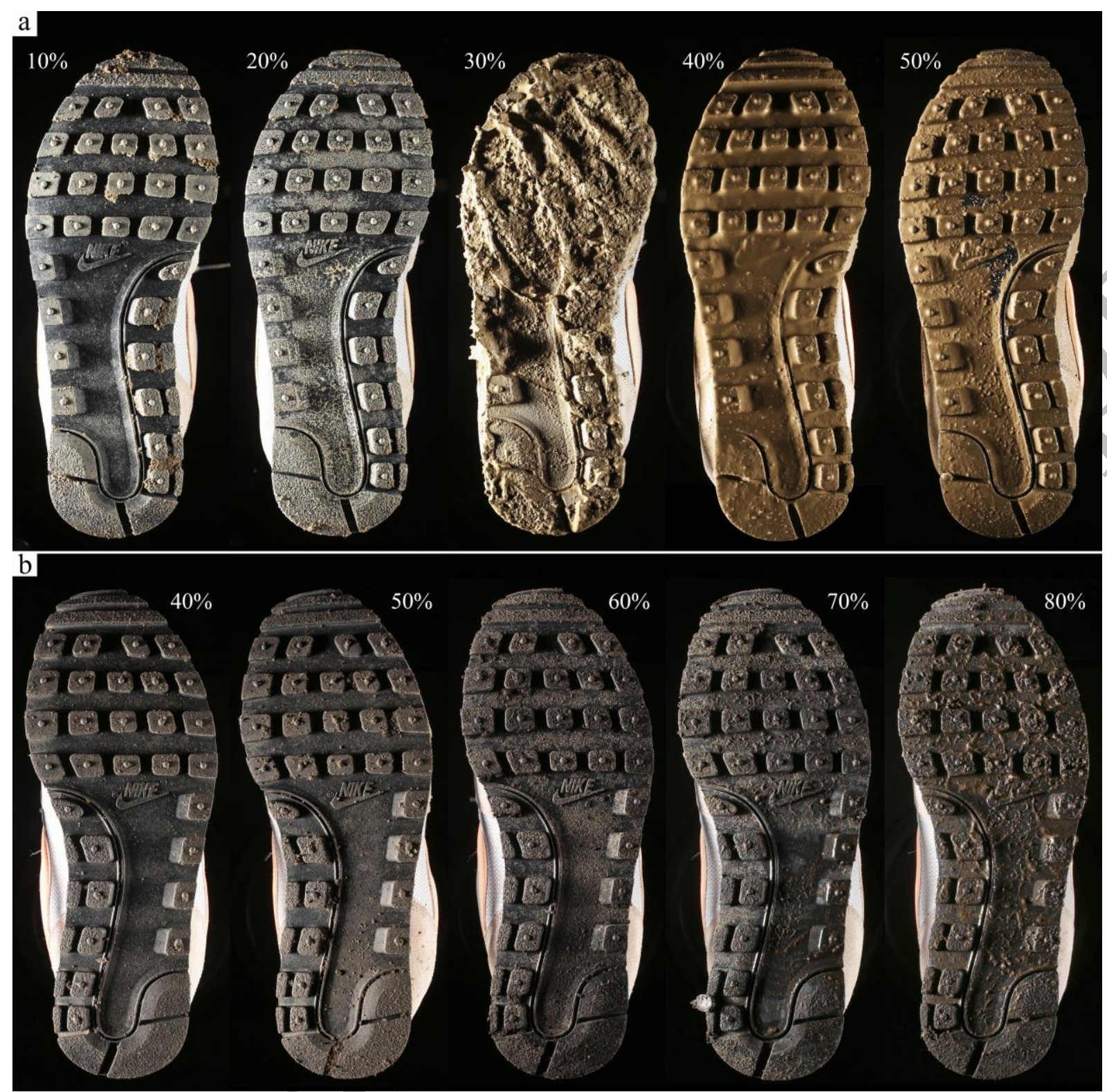

Figure 5. Quantity of soil transferred on Nike Air shoes (size Euro 38) for soil 1 (a) and soil 2 (b) depending on the humidity. Maximum soil transfer was reached at $30 \%$ (a) and $60 \%$ (b) humidity.

\section{Discussion}

The results obtained for both designs indicate that factors linked to the donor - soil type, soil humidity and combinations of both - were the most influential and significantly impacted the amount of soil transferred. The factors linked to the receptor - shoe profile, shoe size and weight of the person wearing the shoes - also had an influence, but these were found to be less important than the donor factors.

\subsection{Discussion of the design of experiments}

The FCCD quadratic models were found to be highly significant, thus they could be adequately used to model and to interpret the amount of soil recovered from one shoe.

Some limitations were highlighted in Section 3.2 concerning the high variability observed for the chosen centre points. Figure 4 shows the influence of the humidity for both soils 1 and 2 and their maxima of transferred soil. For the mixed 
soil sample used as the centre points (50:50\% of both soils), the maximum amount of soil transferred to shoes was expected somewhere between the two maxima of soil $1(30 \%)$ and $2(60 \%)$. As the chosen centre points for humidity were set at $40 \%$ it was expected that it would be around the maximum of this mix soil sample. The variation expected around the maxima and observed at the central points of this mix soil was the highest. Figure 6 is an illustration of the amount of soil transferred at the centre points.

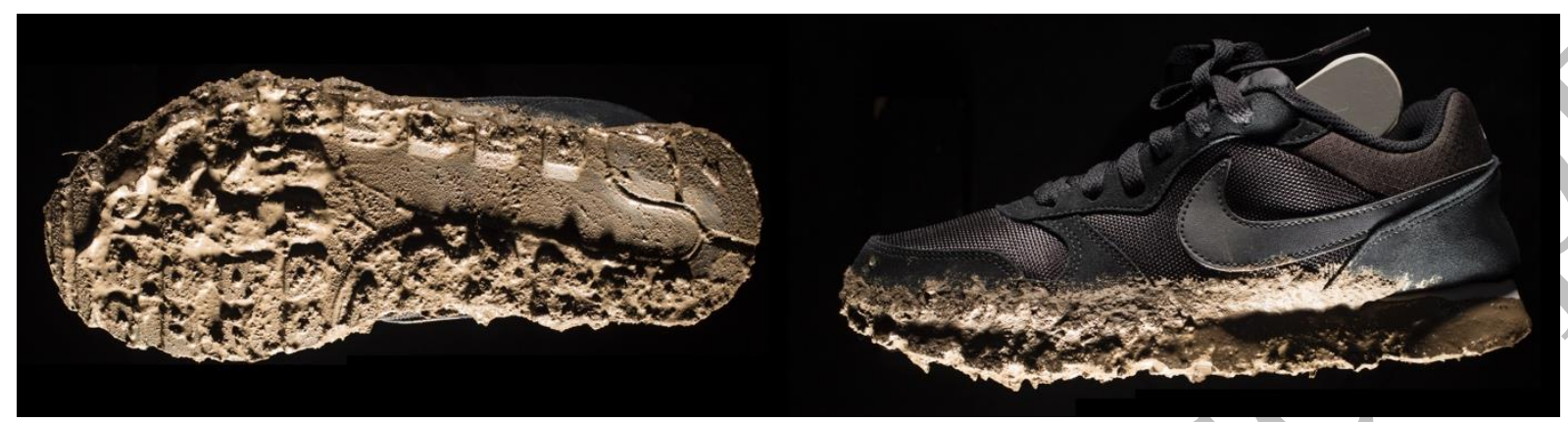

Figure 6. Soil uptake on the sole and the side of a medium profile shoes (Nike Air, size $40,62 \mathrm{~kg}$ ), mix soil type, $40 \%$ humidity.

In our design, the chosen level values for humidity (25\% - low level and $55 \%$ - high level) did not represent the full range of variability for both soils as the maximum for soil $2(60 \%)$ was not included. More complex and adequate models may be able to better represent the impact of humidity and soil. One limitation of our models was illustrated by Figure $3 \mathrm{c}$, showing the amount of soil transferred as a function of soil types and humidity with only one maximum at $40 \%$ for the mix soil. If the soil type and humidity factors are studied more precisely, Figure 4 indicates that three maxima should be present in the surface response: one at $30 \%$ for soil 1 , one at $40 \%$ for the mix soil and the last one around $60 \%$ for soil 2. This illustrated the need for a more complex model to better represent humidity and soil interactions.

\subsection{Factors linked to the receptor}

\subsubsection{Shoe profile}

The effect of the shoe profile was positive in the FCCD in its quadratic form. By referring to Figures $3 a$ and $3 b$, the maximum amount of soil transferred was found to be slightly higher for the low profile shoes - Converse ${ }^{\circledR}$ All Star than for the high profile ones - Swiss Military shoes. The medium profile shoes exhibited a lower amount of soil. These results were confirmed when looking at the raw data in our transfer experiments.

It was interesting to note that low profile shoes presented more transfer than high profile ones, whereas medium profile had significantly lower amount of soil transferred (Figure 3a). These results were unexpected, as an augmentation of soil amount was expected. We formulated here under multiple hypotheses considering those results:

1) The profile was not as important as expected. Some other properties like adherence, surface roughness, and softness, material composition or design and pattern of the sole might be playing an important role in soil adherence.

2) The impact of the composition of the upper part of the shoes (textile vs leather) may impact the amount transferred, especially when soils were wet and the mud would cover the shoes and be absorbed differently [19].

Figure 7a shows both types of shoe soles after transfer experiments with the same soil and humidity. It could be seen that the profile was not as important as expected and that some other properties like adherence, surface roughness, and softness or material composition were playing an important role in soil adherence. Moreover, for soils with a high humidity content 
(over the water saturation), the soil was getting on the shoe material itself (Figure 7b). Again, the adherence properties of the Converse ${ }^{\circledR}$ textile seemed higher than the leather of the Military shoes. More work is clearly required in order to better understand the interactions between soils, shoe profiles and material types.

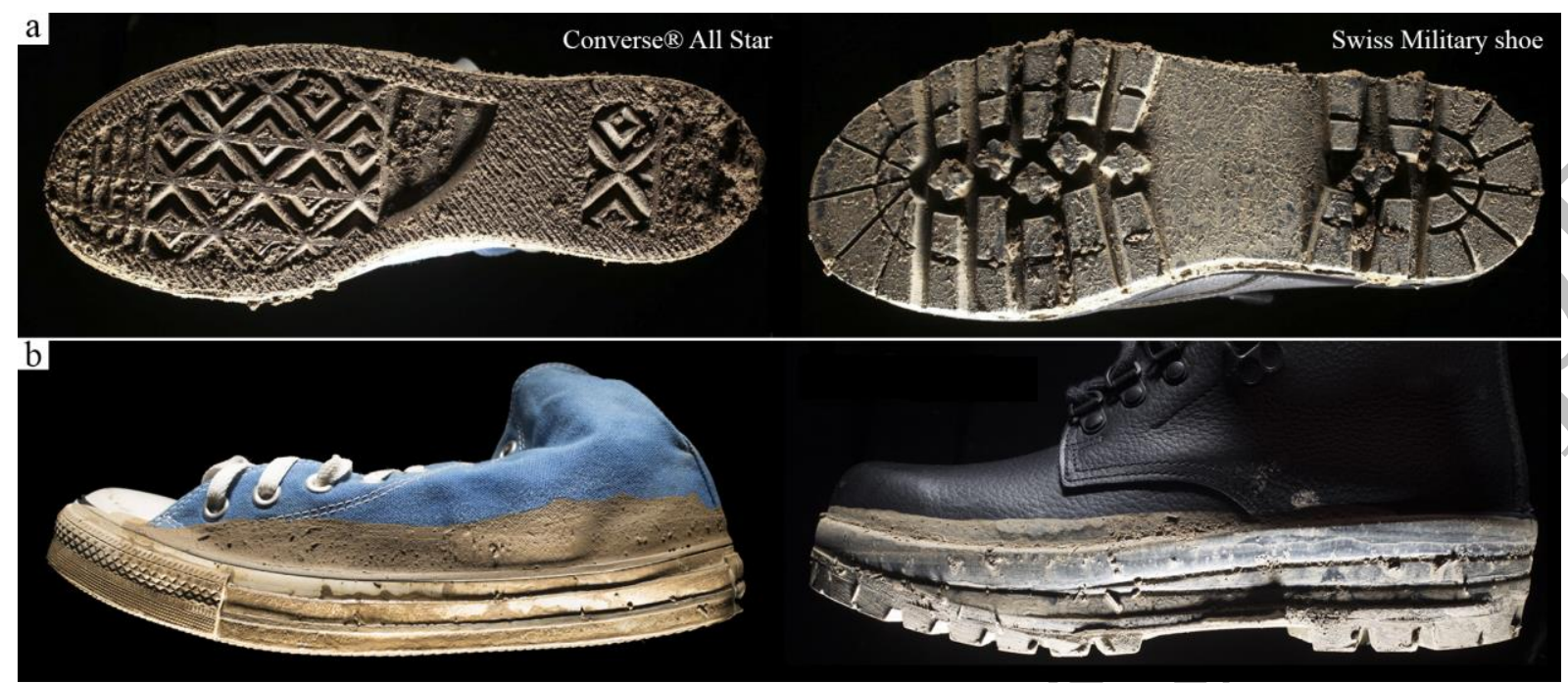

Figure 7. Soil uptake on the sole (a) and the side (b) of a low profile shoe (Converse All Star) and on a high profile shoes (Military shoe), left shoes, soil type $1,20 \%$ (a) and $55 \%$ (b) humidity.

\subsubsection{Shoe size and weight of the person wearing the shoes}

The FCCD showed that there was a positive impact of the shoe size and the walker's weight, especially in their quadratic forms (Table 3), on the quantity of soil transferred. The quantity of soil was expected to be higher when the shoe size or the weight was increased. The raw data showed a moderate impact of both factors.

Moreover, the range of sizes was rather limited in this study (EUR 38 to 42) and it should be extended to better represent male criminals' shoe sizes as described in [34]. This is also the case for weights which model women's mean weights but not the men's $[35,36]$.

\subsection{Factors linked to the donor}

\subsubsection{Soil type}

Both soils had a silty loam texture but their measured characteristics differed. The highly negative effects highlighted in the FCCD, especially in its quadratic form (Table 3 - Effect value) indicate that the quantity of soil transferred is higher for a low organic content soil (soil 1, field, $4.05 \%$ TOC) than for one with a higher organic content (soil 2, forest, 12.1 $\%$ TOC). These two types of soil differ mainly in their total organic carbon content (TOC) but also in their particle size distributions (Table 1). Soil sample 1 had a higher clay proportion (5.7 \% clay) than sample 2 (0.3\% clay). Murray et al. studied a larger sample set and highlighted that soils with higher clay content showed an increase of the quantity of soil particles transferred on fabrics [19]. Moreover, fine clay-sized particles had a greater adherence on fabrics regardless of soil moisture. The same tendency was also observed in this study where soil 1, with higher clay content, transferred a larger quantity than soil 2, even though the transfer experiments were different in both studies (walking vs dragging) as well as the receptor types (shoes vs fabrics). 


\subsubsection{Soil humidity}

Humidity, in its quadratic form (Table 3 - Effect value), had an important impact on the amount of soil transferred. The influence of humidity was already well known from soil experts $[19,23]$ as most of the transfer experiments were carried out with wet soils as supported by $[25,26]$. Murray et al. also found that wetting the soil would generally increase the amount of soil transferred, except for brick fragments (although no detail was given concerning the amount of water added to their dry soil samples) [19]. However, the humidity factor in these studies often seemed to be conditioned by the type of soil considered. It is commonly admitted that a higher level of humidity would generate a larger transfer of soil. Thus, as shown in our experimental design, humidity is mainly important when coupled to the soil type, thus confirming results of [19], regardless the receptor type.

\subsubsection{Type of soil and humidity (interaction DE)}

The interaction of these two factors significantly impacted the quantity of soil transferred. These results were in total accordance with the findings of Murray et al., who highlighted that the quantity of soil transferred to fabric using laboratory-dragging experiments was influenced by a combination of the soil type and soil moisture [19]. Our results complete their observation by reporting the quantity of soil transferred.

The results obtained under Section 3.3 indicated that the capacities of soils 1 and 2 to absorb water are different due to their specific composition. This phenomenon was also observed by Al-Shayea who stated that "the cohesion of clayey sand is found to increase with increasing water content to a certain limit, aboye which it decreases" [45]. The highest quantity of soil transferred to shoes was reached just before the saturation of the soils and the type of soil influenced this quantity. Then, when the maximum is reached, this quantity of transferred soil decreased when more water was added (Figure 4). The clay content had an impact on the soil transfer [19], and so did the soil cohesion [45]. When soil is humid, the higher the clay content, the more the consistency, packing and saturation would increase, as water is strongly attracted to the surface of clay particles. In our case, the TOC content would also have an influence on the quantity of absorbed water in soil. Moradi indicated that the soil liquid limit ( $\mathrm{LL}$ - minimum water content at which the soil is still in the liquid state) increased with the amount and type of clay in the soil as well as with the amount of organic carbon [46]. In our study, we noticed that a higher clay content (soil 1, $5.7 \%$ compared to soil 2, $0.5 \%$ ) resulted in increased quantity of soil transferred. Conversely, a higher TOC content (soil 2, $12.10 \%$ compared to soil 1, $4.05 \%$ ) increased the amount of absorbed water, modifying the position of the maximum (Figure 4). Therefore, looking through our results and coupling them to literature reports, both TOC and clay proportions would affect the interaction between a given soil and humidity and thus amount of soil transferred on shoe soles. Nevertheless, more work needs to be done in order to better understand all the important parameters of soils influencing the transfer, as well as their interaction with water.

\section{Conclusion}

Transfer parameters are very important in a forensic context, in either an investigative or evaluative approach, to assess the evidential value of microtraces at the activity level. However, there has been a lack of this type of research for soil. In this article, a systematic approach using DOE was applied to study soil transfer onto shoes. The significance of five factors, their interactions and their effect on the amount of soil transferred to shoes was assessed in two sets of 102 experiments in total. The chosen factors were related to the donor - soil type and humidity - and to the receptor - shoe profile, shoe size, and walker's weight. The results obtained for both designs (FFD and FCCD) indicated that factors 
linked to the donor were the most influential and impacted the amount of soil transferred in a significant manner. The factors linked to the shoe had a smaller degree of influence.

Our results highlighted that the higher the clay content and/or the humidity, the more influence on the quantity of the soil transferred to shoes. The amount of soil transferred was found to increase with humidity to a maximum depending on the soil type. Beyond this maximum, the transferred quantities decreased. The capacity of soils to absorb water was found to be greater if the total organic carbon (TOC) content was higher.

The maximum amount of soil transferred was found to be slightly higher for the low profile shoes (Converse ${ }^{\circledR}$ All Star) than for the high profile ones (Swiss Military shoes), leading to think that adherence, surface roughness and softness, material composition or design and pattern of the sole, would be more important than the profile itself. The chosen shoe sizes and walker's weight ranges showed only a moderate impact on the transfer.

The FCCD quadratic models were found to be highly significant, thus they could be adequately used to model and to interpret the amount of soil recovered from shoes. However, soil is a very complex mixture and more studies are required in order to better understand the complex interaction between soil types, soil measured properties and humidity and their influence on the transfer. Shoe sole properties (profile, roughness, adherence) should also be studied in more detail in order to model their interactions with a particulate material as complex as soil.

Nevertheless, those results should be considered carefully, as they have been tested on few donors and receptor characteristics. Results cannot be extended to any type of soils or shoes as robustness and validation of the proposed model were not evaluated on a larger sample set.

As most crimes occur in the urban environment, transfer studies should also be performed on trace evidence particles (i.e. dust or very small particles $[47,48]$ ) from building yards, garage forecourts, driveways, roads or pavements. Moreover, in real cases, persistence is affecting the recovered soil traces and a loss of material is expected to happen, mainly due to the suspect activities (i.e. movements: walking, running, etc.) and cleaning (as many perpetrators' clean-up after offences). The elapsed time between the offence and the shoes recovery must also be taken into account in the persistence parameter. These persistence parameters need to be evaluated in further studies.

Finally, this study brought to knowledge more information about the transfer process of soil on shoes and the factors which are influencing it. It provides helpful information for forensic scientists to allow investigation and interpretative evaluation, helping investigators to decide whether or not soil traces could be investigated and what to expect in a given set of hypotheses, case scenario and circumstances, including weather conditions.

\section{Acknowledgments}

The authors would like to acknowledge Mr Michael Schnegg, PhD student at the Ecole des sciences criminelles of the University of Lausanne, for his help for the pictures, and Dr Amanda Frick from Ecole des sciences criminelles of the University of Lausanne for correcting the English. This scientific project was supported by the China University of Political Science and Law (Grant Number: 20116040). 


\section{References}

1. Palmer, R. and Burch, H.J. The population, transfer and persistence of fibres on the skin of living subjects. Science \& Justice, 2009. 49(4): pp. 259-264.

2. $\quad$ Pounds, C.A. and Smalldon, K.W. The Transfer of Fibres Between Clothing Materials During Simulated Contacts and their Persistence During Wear. Part I-Fibre transference. Journal of the Forensic Science Society, 1975. 15(1): pp. 17-27.

3. Pounds, C.A. and Smalldon, K.W. The Transfer of Fibres Between Clothing Materials During Simulated Contacts and Their Persistence During Wear. Part III-Fibre persistence. Journal of the Forensic Science Society, 1975. 15(3): pp. 29-37.

4. $\quad$ Roux, C., Chable, J. and Margot, P. Fibre transfer experiments onto car seats. Science \& Justice, 1996. 36(3): pp. 143-151.

5. Roux, C., Langdon, S., Waight, D. and Robertson, J. The transfer and persistence of automotive carpet fibres on shoe soles. Science \& Justice, 1999. 39(4): pp. 239-251.

6. Schnegg, M., Gueissaz, L., Rodriguez, J., Hess, S. and Massonnet, G. Transfer of Fibres onto Knife Blades in Stabbing Events: Distribution and Determination of the Stabbing Sequence. Journal of Forensic Science and Medicine, 2015. 1(2): pp. 84.

7. Schnegg, M., Turchany, M., Deviterne, M., Gueissaz, L., Hess, S. and Massonnet, G. A preliminary investigation of textile fibers in smothering scenarios and alternative legitimate activities. Forensic Science International, 2017. 279: pp. 165-176.

8. Buzzini, P., Massonnet, G., Birrer, S., Egli, N.M., Mazzella, W. and Fortini, A. Survey of crowbar and household paints in burglary cases-population studies, transfer and interpretation. Forensic Science International, 2005. 152(2-3): pp. 221-234.

9. Krausher, C.D.J. Characteristics of Aerosol Paint Transfer and Dispersal. Canadian Society of Forensic Science Journal, 1994. 27(3): pp. 125-142.

10. Allen, T.J., Hoefler, K. and Rose, S.J. The transfer of glass-part 2. Forensic Science International, 1998. 93(23): pp. 175-193.

11. Allen, T.J. and Scranage, J.K. The transfer of glass-part 1. Forensic Science International, 1998. 93(2-3): pp. 167-174.

12. Locke, J. and Unikowski, J.A. Breaking of flat glass - Part 1: Size and distribution of particles from plain glass windows. Forensic Science International, 1991. 51(2): pp. 251-262.

13. Luce, R.J.W., Buckle, J.L. and McInnis, I. A Study on the Backward Fragmentation of Window Glass and the Transfer of Glass Fragments to Individual's Clothing. Canadian Society of Forensic Science Journal, 1991. 24(2): pp. 79-89.

14. Pounds, C.A. and Smalldon, K.W. The Distribution of Glass Fragments in Front of a Broken Window and the Transfer of Fragments to Individuals Standing Nearby. Journal of the Forensic Science Society, 1978. 18(3-4): pp. 197-203.

15. Aardahl, K., Evidential Value of Glitter Particle Trace Evidence. 2003, San Diego: National University.

16. Gross, S., Igowsky, K. and Pangerl. Glitter as a Source of Trace Evidence. JASTEE, 2010. 1(1).

17. Bull, P.A., Parker, A. and Morgan, R.M. The forensic analysis of soils and sediment taken from the cast of a footprint. Forensic Science International, 2006. 162(1-3): pp. 6-12.

18. Lombardi, G. The Death of Countess Agusta in Portofino (Northern Italy) and the Soil from Two Mismatched Slippers. Journal of Forensic Sciences, 2009. 54(2): pp. 395-399.

19. Murray, K.R., Fitzpatrick, R.W., Bottrill, R.S., Berry, R. and Kobus, H. Soil transference patterns on bras: Image processing and laboratory dragging experiments. Forensic Science International, 2016. 258: pp. 88-100.

20. Petraco, N., Kubic, T.A. and Petraco, N.D.K. Case studies in forensic soil examinations. Forensic Science International, 2008. 178(2-3): pp. 23-27.

21. Ruffell, A. and Sandiford, A. Maximising trace soil evidence: An improved recovery method developed during investigation of a \$26 million bank robbery. Forensic Science International, 2011. 209(1-3): pp. e1-e7.

22. Von Däniken, N. Cas "terres" en sciences forensiques. 2015. Bachelor thesis. Ecole des Sciences Criminelles, University of Lausanne.

23. Pye, K., Geological and soil evidence: forensic applications. 2007, Boca Raton, FL: CRC Press.

24. Murray, R.C., Evidence from the earth: forensic geology and criminal investigation. 2004, Missoula, Mont: Mountain Press Pub. Co.

25. Dudley, R.J. and Smalldon, K.W. The evaluation of methods for soil analysis under simulated scenes of crime conditions. Forensic Science International, 1978. 12(1): pp. 49-60.

26. Croft, D.J. and Pye, K. Multi-technique comparison of source and primary transfer soil samples: an experimental investigation. Science \& Justice, 2004. 44(1): pp. 21-28.

27. Chazottes, V., Brocard, C. and Peyrot, B. Particle size analysis of soils under simulated scene of crime conditions: the interest of multivariate analyses. Forensic Science International, 2004. 140(2-3): pp. 159-166. 
28. Morgan, R.M., Freudiger-Bonzon, J., Nichols, K.H., Jellis, T., Dunkerley, S., Zelazowski, P. and Bull, P.A., The Forensic Analysis of Sediments Recovered from Footwear, in Criminal and Environmental Soil Forensics, Ritz, K., Dawson, L. and Miller, D., Editors. 2009, Springer Netherlands: Dordrecht. pp. 253-269.

29. Stoney, D.A., Bowen, A.M. and Stoney, P.L. Loss and replacement of small particles on the contact surfaces of footwear during successive exposures. Forensic Science International, 2016. 269: pp. 78-88.

30. Woods, B., Lennard, C., Kirkbride, K.P. and Robertson, J. Soil examination for a forensic trace evidence laboratory-Part 3: A proposed protocol for the effective triage and management of soil examinations. Forensic Science International, 2016. 262: pp. 46-55.

31. European Network of Forensic Science Institutes, ENFSI guideline for evaluative reporting in forensic science, strengthening the evaluation of forensic results across Europe. 2015.

32. Gentile, N., Besson, L., Pazos, D., Delémont, O. and Esseiva, P. On the use of IRMS in forensic science: Proposals for a methodological approach. Forensic Science International, 2011. 212(1-3): pp. 260-271.

33. Box, G.E.P., Hunter, J.S. and Hunter, W.G., Statistics for experimenters: design, innovation, and discovery. 2 nd ed edition. Wiley series in probability and statistics. 2005, Hoboken, N.J: Wiley-Interscience.

34. Girod, A., Champod, C. and Ribaux, O., Traces de souliers. 2008, Lausanne: Presses polytechniques et universitaires romandes.

35. Bochud, M., Chatelan, A., Blanco, J.M. and Beer-Borst, S., Anthropometric characteristics and indicators of eating and physical activity behaviors in the Swiss adult population. 2017, Federal Office of Public Health: Lausanne.

36. Chappuis, A., Bochud, M., Glatz, N., Vuistiner, P., Paccaud, F. and Burnier, M., Swiss survey on salt intake: main results. 2011, Federal Office of Public Health: Lausanne.

37. International Organization for Standardization. Soil quality - Determination of pH. ISO 10390:2005, 2005.

38. Ma, Y., Qu, L., Wang, W., Yang, X. and Lei, T. Measuring soil water content through volume/mass replacement using a constant volume container. Geoderma, 2016. 271: pp. 42-49.

39. Munsell, C., Munsell Soil-Color Charts with genuine Munsell color chips. 2009 Year Revised edition. 2015, Grand Rapids, MI.

40. Ditzer, C., Scheffe, K. and Monger, H.C., Soil survey manual. Government Printing Office edition. 2017, Washington, DC: United States Department of Agriculture (USDA).

41. Vera Candioti, L., De Zan, M.M., Cámara, M.S. and Goicoechea, H.C. Experimental design and multiple response optimization. Using the desirability function in analytical methods development. Talanta, 2014. 124: pp. 123-138.

42. Gallidabino, M., Romolo, F.S. and Weyermann, C. Time since discharge of 9 mm cartridges by headspace analysis, part 1: Comprehensive optimisation and validation of a headspace sorptive extraction (HSSE) method. Forensic Science International, 2017. 272: pp. 159-170.

43. Ferreira, S.L.C., Bruns, R.E., da Silva, E.G.P., dos Santos, W.N.L., Quintella, C.M., David, J.M., de Andrade, J.B., Breitkreitz, M.C., Jardim, I.C.S.F. and Neto, B.B. Statistical designs and response surface techniques for the optimization of chromatographic systems. Journal of Chromatography A, 2007. 1158(1-2): pp. 2-14.

44. Goupy, J., Introduction aux plans d'expériences: avec applications. 2017, Paris: Dunod.

45. Al-Shayea, N.A. The combined effect of clay and moisture content on the behavior of remolded unsaturated soils. Engineering Geology, 2001. 62(4): pp. 319-342.

46. Moradi, S. Impacts of organic carbon on consistency limits in different soil textures. International Journal of Agriculture and Crop Sciences, 2013. 12: pp. 1381-1388.

47. Stoney, D.A., Bowen, A.M., Ausdemore, M., Stoney, P.L., Neumann, C. and Stoney, F.P. Differential analysis of very small particles (VSP) from the contact surfaces and recessed areas of footwear. Forensic Science International, 2019. 298: pp. 106-114.

48. Stoney, D.A., Bowen, A.M., Bryant, V.M., Caven, E.A., Cimino, M.T. and Stoney, P.L. Particle combination analysis for predictive source attribution: tracing a shipment of contraband ivory. Journal of the American Society of Trace Evidence Examiners, 2011. 2(1): pp. 13-72. 